\title{
Emergency consultations for malfunctions of the masticatory apparatus
}

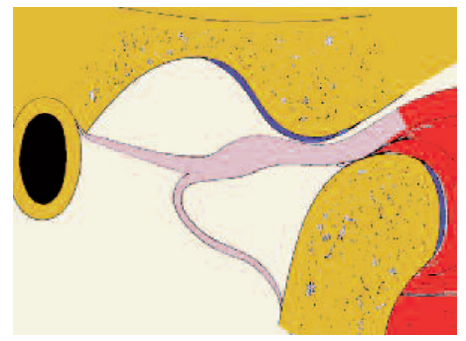

\author{
Olivier LAPLANCHE, Pierre PEDEUTOUR, \\ Gérard DUMINIL, Elodie HERMANN
}

\section{ABSTRACT}

The masticatory apparatus, which serves numerous functions in the life of humans, is constantly active and, as a result, can be the victim of a variety of malfunctions, even trauma. which occurs suddenly, often brutally enough to provoke patients to seek a consultation with a specialist in the masticatory apparatus, that is, an orthodontist.

What attitude should we adopt when examining a patient with myalgia, a subluxated or "locked" mandible, or sudden onset of arthralgia, pain in the temperomandibular joint? Finesse in clinical diagnosis and a profound knowledge of disorders of the masticatory apparatus are essentials in dealing with emergency visits from patients who have suffered a traumatic incident. We should devise prompt, prudent, and appropriate treatment to help them.

\section{KEYWORDS}

Emergency,

Therapy,

Disorders of the masticatory apparatus,

Limited opening of the jaw,

Locking or subluxation of the mandible. 


\section{1 - INTRODUCTION}

All orthodontists, in their capacity of specialists in the masticatory system, will sooner or later have to manage the pain of one of their patients suffering from an "occlusodontic emergency" or the distress of a new patient referred by medical colleagues or other patients.

These clinical situations may range from mandibles that are locked in an open or a shut position, strong or moderate limitation of opening the jaw, arthralgia, to muscular and periarticular pain.

To deal with them orthodontists should rely first on general principles they learned in their professional training, on a careful case history covering the first appearance of the disorder and the pain it has caused, and then on a precise clinical examination clarified by their profound knowledge of the masticatory system, especially its anatomy and physiology.

\section{2 - DIAGNOSTIC DIFFICULTIES AND THERAPEUTIC OBJECTIVES}

Occlusodontic emergencies are similar to traditional medical emergencies and generally require practitioners to act in a tactful and delicate manner because no matter what the particular circumstances may be - spontaneous, accidental, or traumatic causes of the disorder - the symptoms are usually acutely dolorous and anxiety provoking for patients who are subjected not only to pain but also to a handicapping loss of function ${ }^{26}$.

\section{2 - 1 - Special requirements of emergency visits}

Orthodontists should attempt to minimize these problems by:

- using soothing psychological techniques, reassuring patients about their condition and detailing the treatment solutions that are available for it;

- establishing a differential diagnosis that distinguishes functional anomalies of the masticatory system from symptoms of other generalized pathologies (Is this a tempero-mandibular joint disorder, TMD, or is it something else ${ }^{13-26}$;;

- establishing a positive diagnosis (type of pathology) ${ }^{23}$;

- establishing a therapeutic regimen, if possible immediately, to reduce pain and restore at least minimal function by eliminating impediments to it ${ }^{26}$;

- establishing a schedule of follow-up appointments during which they can optimize the diagnosis ${ }^{25}$ in order to make an accurate diagnosis and institute treatment if indicated.

\section{2 - 2 - Fundamental principles}

Orthodontists should keep in mind some special fundamental principles applied to emergency visits.

\section{- Diagnosis is more difficult than in routine examinations}

The special circumstances obtaining during an emergency visit making it 
impossible for orthodontists to carry out complete diagnostic procedures, such as supplementary studies, like medical imaging or kinesthesiology and biological studies, a precise intake interview and the clinical exam become even more essential than ever ${ }^{19,32,38}$.

Distressed by the emotional as well as the physical trauma of the event that provoked the emergency visits, patients often react in a distraught manner to the examiner's questions and to palpations in a way that can give false positives.

\section{- Etiology of malfunctions of the masticatory system}

The etiology of TMD is multi-factorial. There is today a wide consensus that occlusion plays a role in joint disturbances but a minor one. In emergency situations orthodontists should no longer consider a study of occlusion, once a primordial underpinning of dental thinking, to be a priority in their diagnostic protocol, which does not mean they should not consider it, at the correct level of its probable importance, nor should this new assessment of occlusion's relative importance prevent them from accomplishing a complete dental and oral cavity examination which is essential for the differential diagnosis.

\section{- Diagnostic prudence}

Orthodontists must make careful differential diagnoses in all disorders occurring in the cranio-orofacial area because many maladies may provoke identical clinical symptoms with, of course, the most unfavorable diagnosis demending the most prompt attention. A diagnosis of TMD becomes, accordingly, one of exclusion.

Signs of malfunction of the masticatory system are frequently encoun- tered in the general population, with $80 \%$ of all people presenting at least one such indication, but only $3 \%$ suffering severely enough from them to require treatment ${ }^{13}$.

Confronting the legitimate anxiety of patients consulting them for an emergency problem, orthodontists must distinguish between the appearances of a single, benign, expression of a transitory disturbance from an indication of a serious underlying malady ${ }^{4-29}$.

\section{- Therapeutic prudence}

Even though patients on an emergency visit may insist that they receive immediate treatment, orthodontists must be guided by the prudence imposed in the fundamental medical axiom, primum non nocere, first do no harm.

They must also avoid any therapy for trauma, like forcible manipulation of the mandible or non-reversible grinding of supposed prematurities ${ }^{2-}$ 25 that are not deemed advisable by a careful cost-benefit analysis.

\section{- Therapeutic moderation}

The short-term objectives of management of emergency patients suffering from acute disorder of the masticatory system are relief of pain and minimizing the functional deficit. More ambitious therapy should be delayed until after reevaluation of the problem in the framework of traditional diagnostic procedures and the suitability of possible therapies ${ }^{2}$.

\section{- Basic concepts of TMD therapy}

Orthodontists should never initiate invasive and irreversible treatment for acute TMD problems but instead focus on helping patients "survive the crisis" and offering symptomatic 
relief by reducing pain and improving both function and prognosis ${ }^{26,31}$.

\section{- Psychological management}

In addition to the discomfort and loss of function, emergency patients suffer, perhaps more dramatically, from an inability to comprehend what has happened to them with its accompanying anxiety and from uncertainty about possible treatment. It is essential for orthodontists to reassure them, to explain the parameters of the situation, and later, when indicated, to prescribe medication and to begin managing the disorder under optimal conditions $^{26-28}$.

\section{- Reevaluation 6}

In all in cases, no matter what therapeutic solutions may or may not be indicated, orthodontists should schedule a reevaluation appointment shortly after the emergency visit ${ }^{4,9}$.

\section{3 - DIFFERENT TYPES OF EMERGENCIES AND HOW ORTHODONTISTS SHOULD DEAL WITH THEM}

The occlusodontic emergencies most encountered, characterized by the most evident symptom, are described in Table 1. In each of these clinical situations these elements can be delineated:

- motive for the consultation and type of onset of the problem,

- clinical signs,

- diagnosis,
- etiology of the disorder,

- therapy.

No matter what the clinical situation may be, orthodontists should follow this time-tested protocol:

- careful intake history, if an oral appliance is involved, its history, specific history of the emergency, when did it appear, was there a precipitating factor?

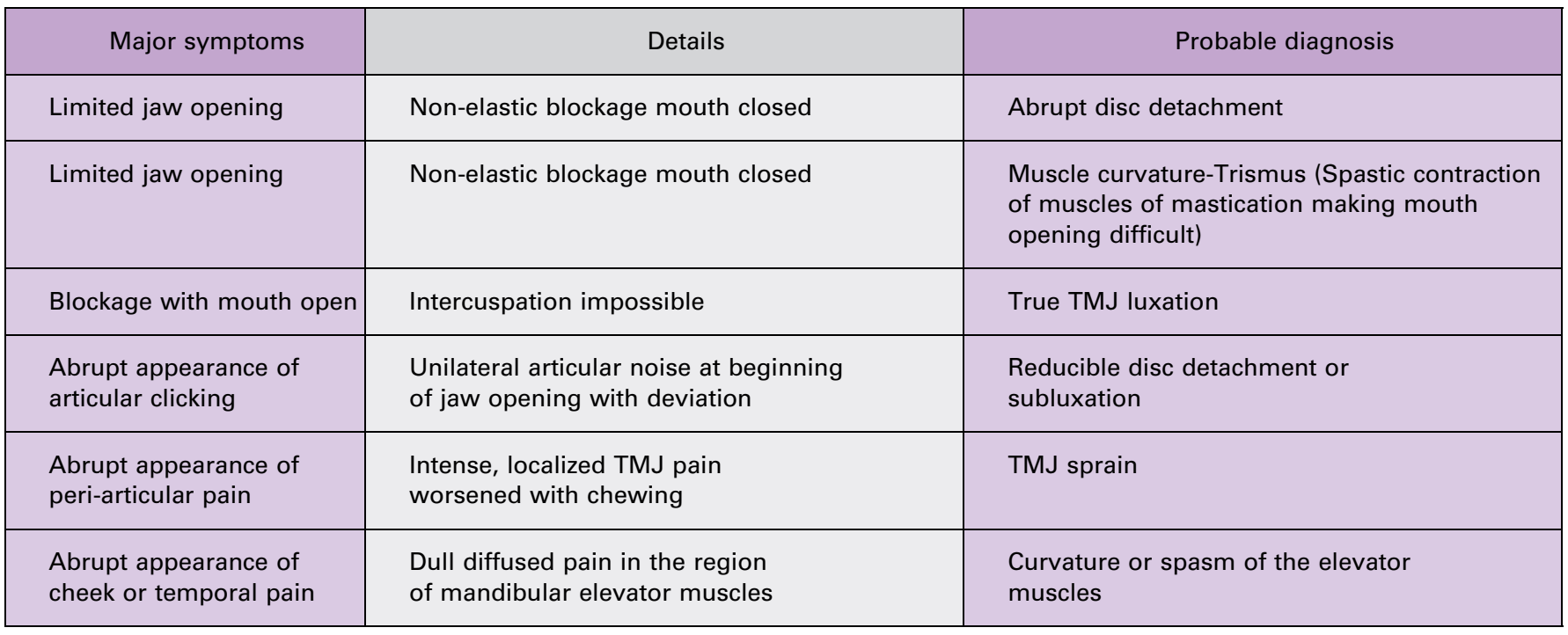

Table 1 
- precise clinical examination of the masticatory apparatus, the tempero-mandibular joint, and, eventually, clinical tests ${ }^{36}$.

\section{3 - 1 - Limited opening of the mouth: rigid closure of mouth}

\section{- How the problem started}

An abrupt beginning of the severe blockage $^{3}$ with pain in the joint.

Patient had described clicking sounds coming from the joint in the intake history that did not recur after the blockage.

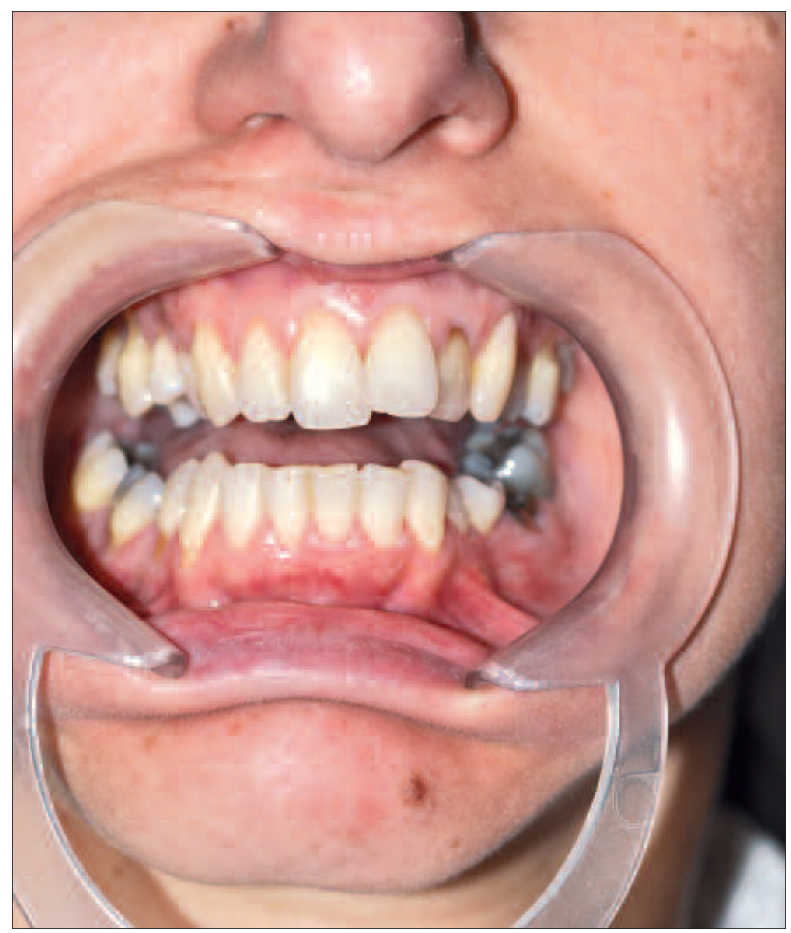

Figure 1

Patient has limited ability to open and does so with a marked deviation.

\section{- Clinical signs ${ }^{4}$}

- Moderate to severe TMJ pain, increasing with muscle-guided functional movement and tenderness to practitioner's palpating the joint or mobilizing the mandible.

- Limited jaw opening, less than $30 \mathrm{~mm}$ with asymmetric deflection of the jaw (fig. 1).

- The elastic resistance test in forced opening is negative (fig. 2) and painful.

- Intra-auricular and lateral articular palpation is painful.

\section{- Diagnosis}

- Permanent acute condyle-disk displacements (Okeson).

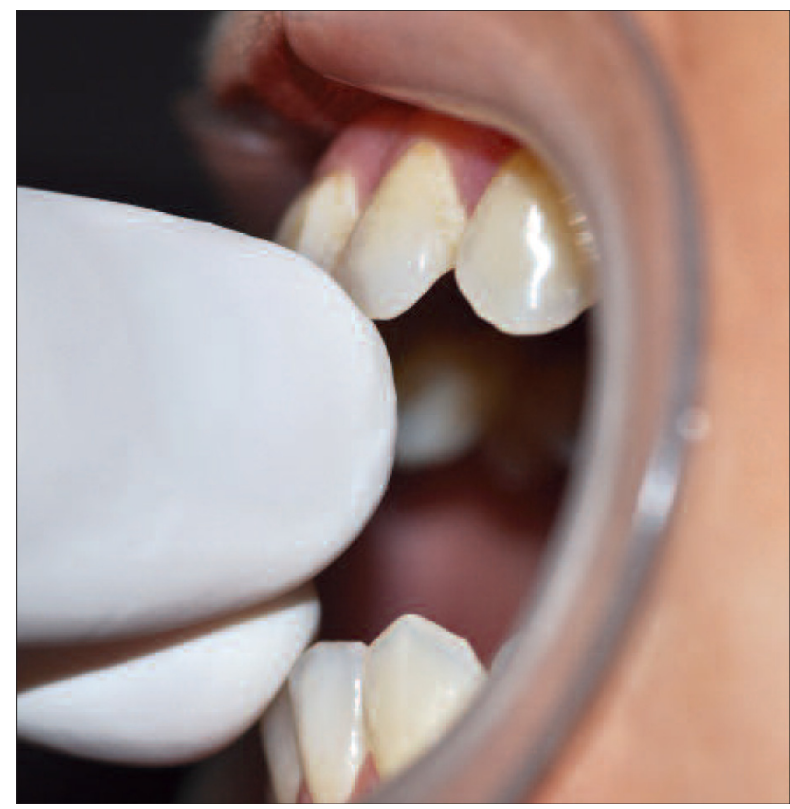

Figure 2

Clinicians execute a resistance test by gently trying to increase jaw opening. Rigid resistance to this is a sign of the presence of an intra-articular obstacle such as an anteriorly displaced disc. If the patient's resistance is non-rigid, or yielding, this is a sign of spasm of the elevator muscles ${ }^{10}$. 
- Abrupt onset and retention of mandibular movement, even if limited distinguish it in a differential diagnosis from true tempero-mandibular joint ankylosis ${ }^{5}$, 6,7 which does not constitute an emergency problem,

- A negative elastic resistance test and the impossibility of propulsive mandibular movements as well as lateral movement in direction opposite the site of disk displacement distinguish it in a differential diagnosis from spasm of the elevator mastication muscles ${ }^{10}$.

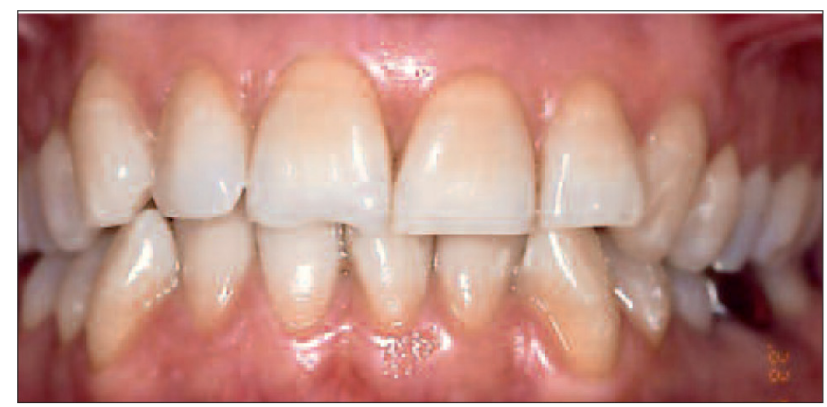

a

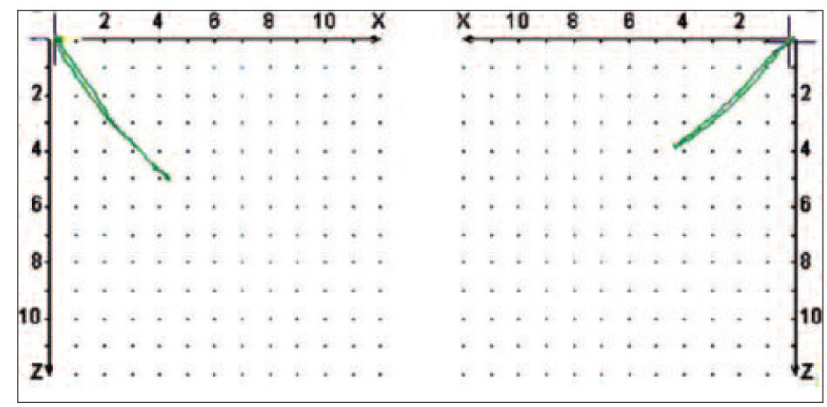

C

\section{- Etiology of the pathosis}

- A rapid onset of permanent condyle-disk displacement often following history of similar displacements that were successfully reduced ${ }^{12,23}$

- Stretching of the disk ligament provoking inflammation of the articular capsule.

- In maximal inter-cuspation the condylar retro-position compresses the bilaminary zone and causes inflammation of the disc tissues provoking pain especially if the disk displacement had not been preceded by
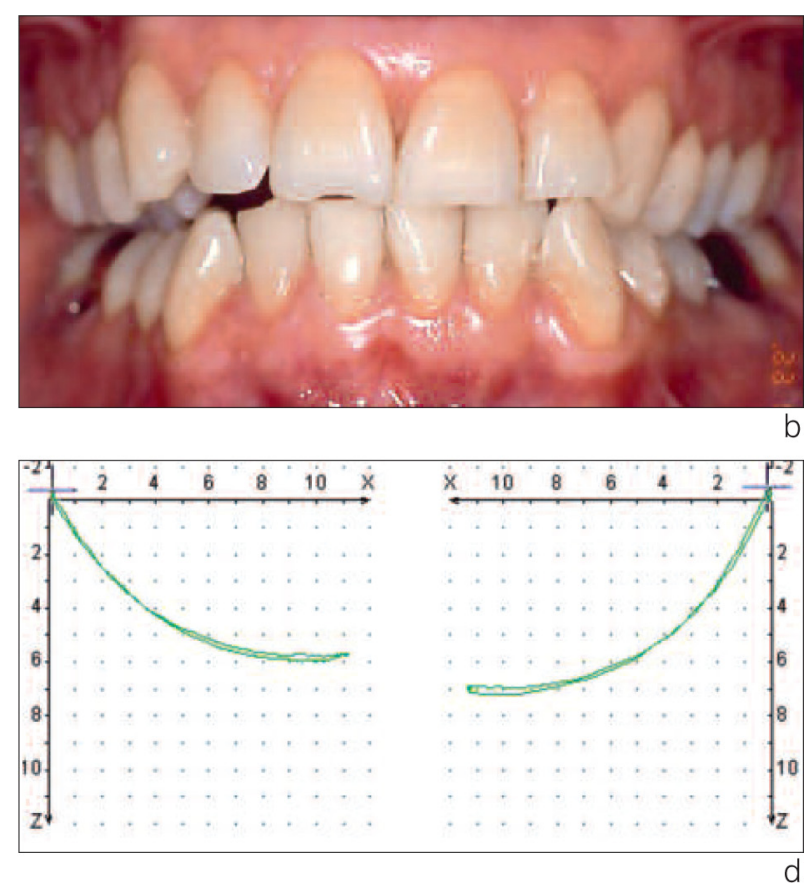

Figures 3 a to $d$

The clinician asks patients to thrust their jaws forward in a propulsion test.

In figure a the propulsion and jaw opening are quite limited, a sign of articular malfunction caused by blocked condylar translation.

In figure $b$ the propulsion is normal but opening is limited, a sign of muscular malfunction.

Figure $c$ depicts an electronic condylograph showing limited condylar translation in opening compared to a normal translation in figure $d$. 
episodes of displacements successfully reduced (fig. 4 to 6).

- The anterior position of the disc interferes with condylar translation causes a deflection of the jaw in opening toward the affected side and limits jaw opening as well as propulsive and contra-lateral mandibular movements.

\section{- Therapy $^{35}$}

The FARRAR (fig. 7 a and b) maneuver, which is used in an attempt to re-unite the displaced disk and condyle, is only indicated when the displacement occurred recently, a

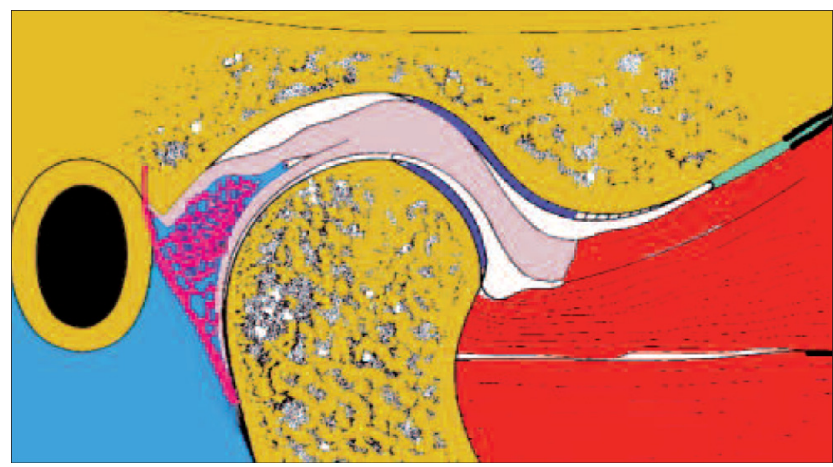

Figure 4

Sketch of a healthy TMJ. few hours or at most a few days before the consultation and has not been preceded by previous displacements successfully. Orthodontists should employ it with great caution.

- If the maneuver succeeds and inspection reveals that an occlusal factor is clearly responsible the orthodontist is justified in making a diagnosis of major occlusal interference. Treatment would consist of an inter-occlusal orthesis or plastic bite block preventing the mandible from assuming a retroposition. This temporary device can be considered to be the

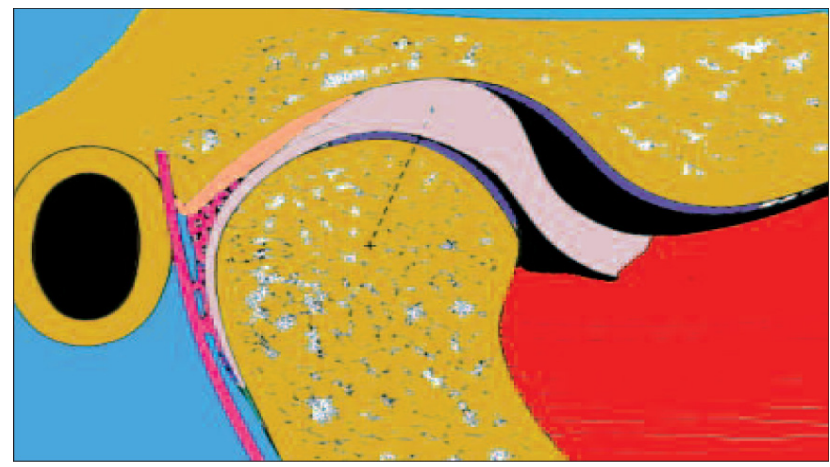

Figure 5

Sketch of a TMJ with condyle positioned distally and compression of the bilaminary zone.
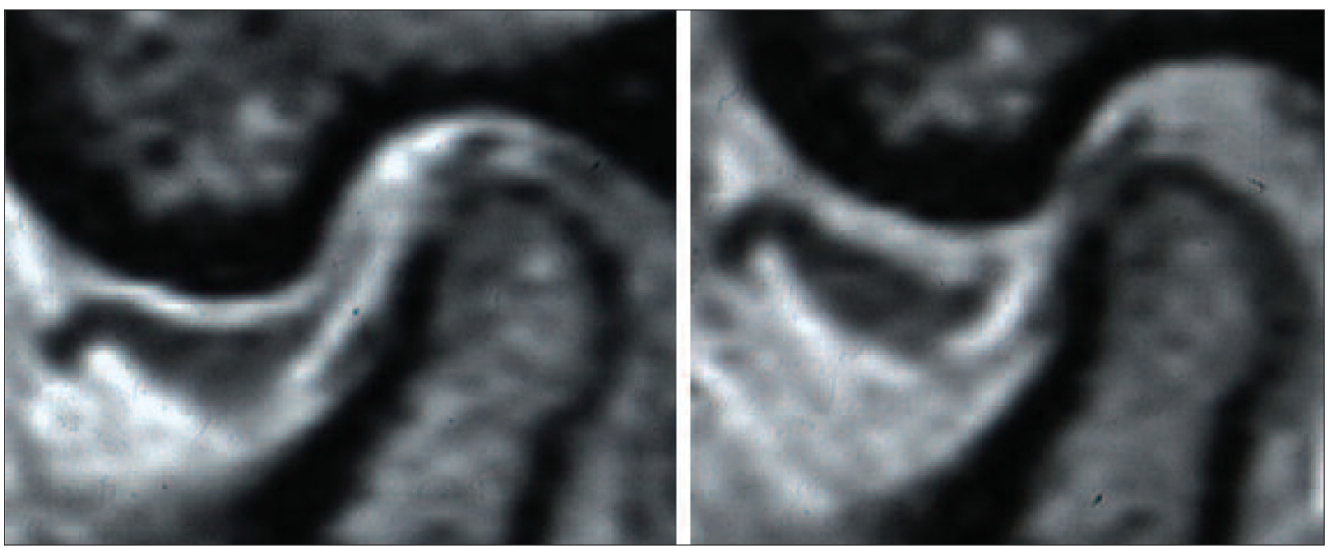

Figure 6

MRI of a patient's left TMJ that shows permanent disc displacement. 

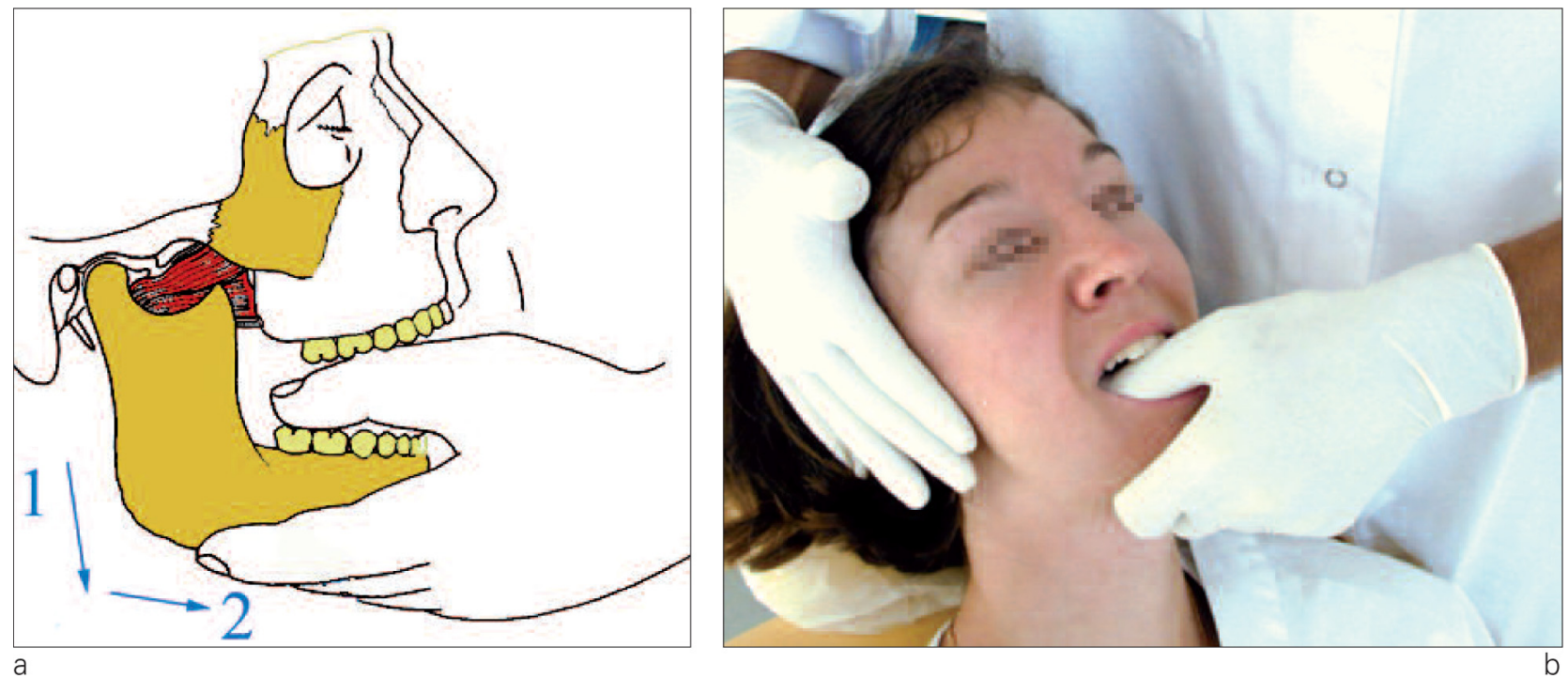

Figures $7 a$ and $b$

a: sketch of Farrar manoeuver

b: photo of clinician performing Farrar manoeuver.

equivalent of a crutch to be used for a few days until more definitive therapy can begin.

- If the maneuver doesn't succeed, this orthesis can be employed as well to stimulate articular decompression gently:

- orthodontists may attempt to resolve the problem by muscle retraining, using myo-functional therapy and by offering behavioral counseling.

- treatment with medication: local analgesics and non-steroidal antiinflammatory ${ }^{1}$,

- resting the joint to reduce inflammation and limiting mandibular movements,

- helping patient to become aware of and suppressing habits like clenching and bruxism.

In a second stage the orthodontist will plan multi-pronged treatment of the articular malfunction ${ }^{2,25}$.

\section{3 - 2 - Limited mouth opening: non-rigid blockage, mouth closed rigidly}

\section{- Reason for consultation}

Patient has rapid onset limited opening of jaw, similar to rigid blockage.

\section{- Clinical signs}

- Limited mouth opening (fig. 1).

- Moderate to intense pain in elevator muscles, principally the masseters, less frequently the temporals, exacerbated by function.

- Pain in the elevators muscles on attempts at forced opening.

- The elastic resistance test ${ }^{17}$ on forced opening is positive (fig. 2): the practitioner can by exerting light pressure on the incisal edges of the upper and lower anterior teeth, increase mouth opening by a few millimeters. 
- The history reveals that the patient had experienced intermittent sensations of muscle fatigue or pain indicating curvature of the elevator muscles.

\section{- Diagnosis}

- Spasm or splinting reflex of the elevator muscles ${ }^{28}$.

\section{- Etiology of the pathosis}

It appears that multiple factors participate in the etiology of temperomandibular joint disorders:

- local factors such as muscular fatigue and lack of electrolytic equilibrium: contraction seems to be responding to an exaggerated excitation of alpha motoneurones, creating a cycle of pain-spasm-pain. The resultant ischemia leads to contraction that fatigues muscles, forming lactic acid and liberating bradykinins;

- systemic factors: unknown systemic problems may make some people overly susceptible to spasms;

- transitory occlusal instability associated with orthodontic treatment could be the cause of this type of temporary muscular reaction.

\section{- Treatment $^{16}$}

The multi-pronged management of acute muscular malfunction includes:

- explaining to patients the nature of the situation and offering them advice on what actions they can take to defuse the problem,

- medications like peripheral analgesics and muscle relaxants ${ }^{5}$,

- gymnotherapy, an originally Japanese type of physical therapy and kinesitherapy, passive mobilization of the mandible,
- Immediate anterior occlusal splint or an immediate interocclusal orthesis made at the chair.

\section{3 - 3 - Blockage with mouth open}

\section{- Motive for consultation}

Patient suddenly found it was impossible to close jaw (it was not possible for patient to move the mandible into a position of maximum intercuspation.)

\section{- Clinical signs}

- Jaw held open, the mandible and its teeth cannot be moved into contact with maxillary teeth, being kept 1 to $3 \mathrm{~cm}$ apart at rest and in slight propulsion. Maximum intercuspation cannot be achieved.

Peri-articular pain is intense and both muscular and articular pain are exacerbated by palpation.

- The history often reveals an exaggerated and generalized muscular laxness and episodes of subluxation that patient could reduce with clicking in maximal opening ${ }^{11}$.

- Rapid onset of condition in relation to maximum opening caused by yawning or attempt to masticate large food bolus.

\section{- Diagnosis}

- True tempero-mandibular, or condylar luxation: the head of the condyle passes beyond the articular eminence. This may be unilateral or bilateral (fig. $8 \mathrm{a}$ and b). 

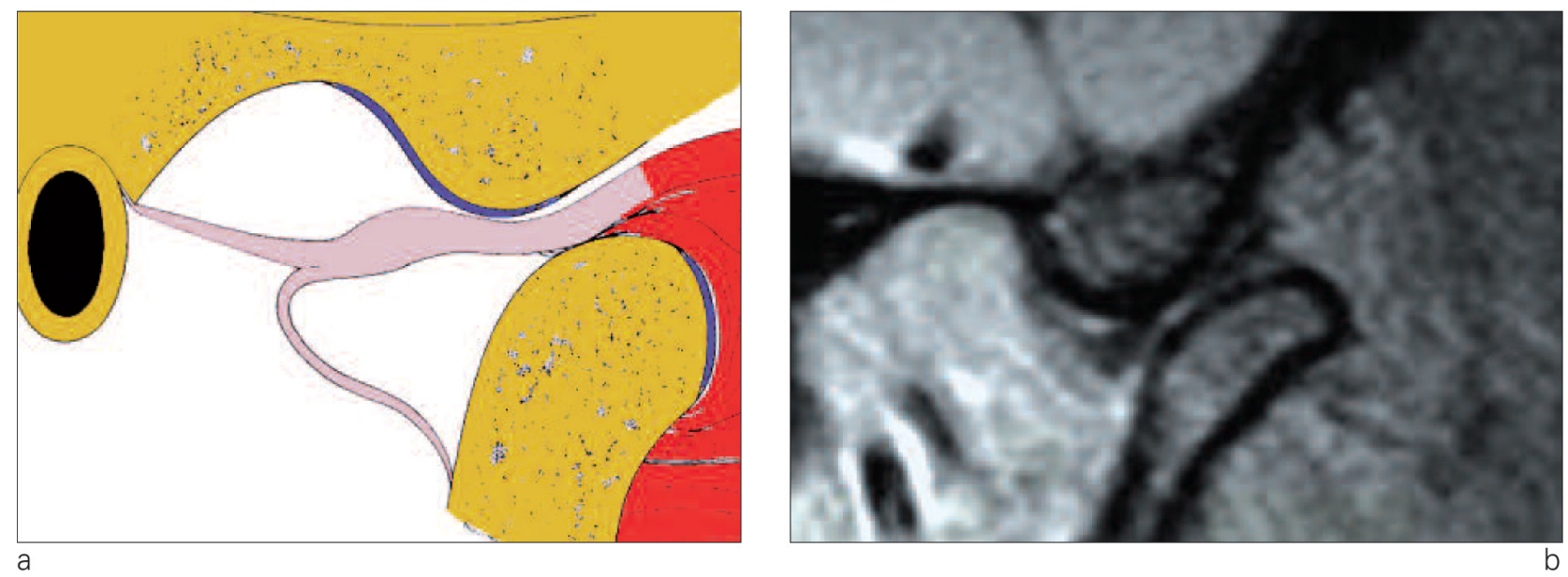

Figures 8 and $b$

a: sketch of a true TMJ luxation.

b: MRI of true TMJ luxation or sub-luxation. The condyle is substantially beyond the articular eminence and cannot regain its place in the temporal fossa.

\section{- Etiology of the pathosis}

- Because the ligament is highly stretched, the head of the condyle may pass beyond the articular eminence; this hyper-extension triggers a reflex spasm of the elevator muscles that prevents spontaneous return of the condyle to its normal position.

\section{- Treatment}

- Reassure the patient and explain the diagnosis to help reduce patient's anxiety.

- Attempt Nelaton "drawer maneuver" to restore the condyle to its correct position (fig. 9 a and b).

- A bite block preventing excessive translation of the condyle may eventually be indicated after reduction of the luxation.

- Counseling on how to prevent excessive opening of jaw,

- Analgesics for peripheral pain ${ }^{1}$,

- Kinesitherapy and gymnotherapy designed to strengthen the elevator muscles and reduce stretching, or laxness, of muscles.

- Should the Nelaton maneuver fail, general anesthesia or an anti-anxiety perfusion, $5 \mathrm{mg}$ Diazepam, for example, and even curare type muscle relaxants may be needed to obtain total muscle relaxation to facilitate reduction of the luxation.

\section{3 - 4 - Rapid onset of jaw clicking}

\section{- Conditions of onset of disorder}

Sudden onset of perceptible clicking in the TMJ in mandibular movements

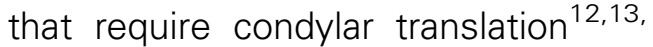
23,28

The clicking may follow a triggering incident such as moderate shock, a long dental appointment with mouth open, chewing on a hard bit of food or may commence for no apparent reason. 

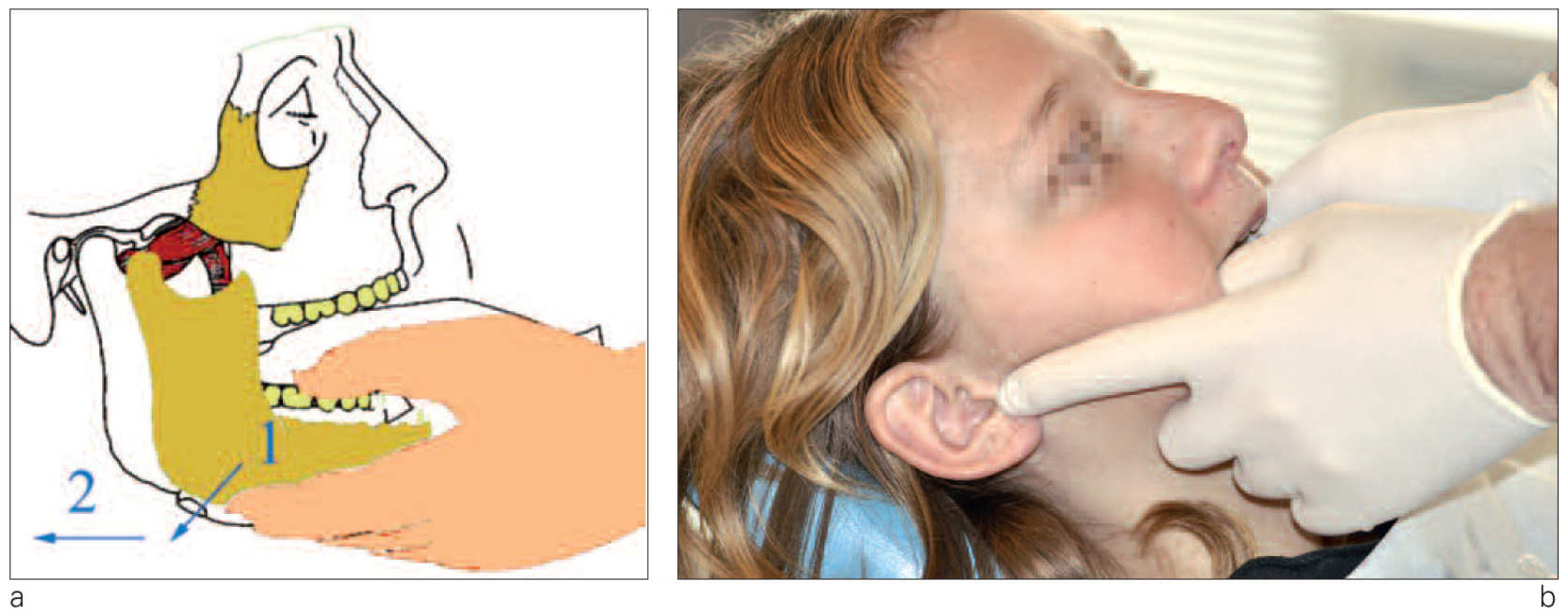

Figures $9 a$ and $b$

a: sketch illustrating Nelaton maneuver.

$b$ : clinician performing Nelaton maneuver.

\section{- Clinical signs}

- Clicking, usually unilateral, as the mandible approaches intercuspation.

- On testing articular compression by exerting pressure on the menton area as the mandible shifts to the side of clicking, the examining orthodontist may get a positive indication of retro-articular pain.

- Sometimes the clicking is not accompanied by any other clinical sign.

- The clicking usually disappears when patient moves mandible to an anterior position.

- Sometimes no other clinical sign accompanies the clicking (cf. infra: clinical test 1).

- Clinical examination may reveal a slight over-occlusion, or prematurites of some teeth related to absence of disc covering condyle on one side in maximal intercuspation that causes homolateral ascension of the this condyle and the dental arch.
- Clinical test $\mathbf{n}^{\circ}$ 1: have patient open jaw as widely as possible and then close gently in 1 or $2 \mathrm{~mm}$ of propulsion and not attempt to achieve intercuspation. From this point the patient should be able to lower and raise the mandible with no joint clicking, because the displacement of condyle and its disc has been temporarily repaired.

- Clinical test $\mathbf{n}^{\circ}$ 2: palpate the joint and the condylar trajectory as patient slowly opens jaw. If there is an abrupt leap of the condyle as maximum opening, of up to $45 \mathrm{~mm}$, approaches, it is likely that the clicking sound indicates the point of subluxation.

\section{- Diagnosis}

- If the displacement of the condylar disc can be reduced ${ }^{12}$ a differential diagnosis of subluxation can readily be made and constitutes a 
preliminary prerequisite for subsequent treatment.

\section{- Pathological etiology}

- The displacement of the disc from the condyle is associated with a stretching of the condylar ligament or an abrupt distal positioning of the condyle resulting from the trauma of a blow or micro-traumatic incidents occurring during sleep or in the course of some habit, or simply be an obscure manifestation of a growth discrepancy.

- Tension in the three muscle groups, temporal, masseter, and ptyergoid, related to the condyle-disc complex $^{14}$ may be implicated in the etiology. But, as a rule, TMD appears after some triggering incident occurs in an environment favoring its development;

- A transitory, reversible malposition of the mandible occurring during tooth movements of orthodontic treatment can play the role of a triggering factor ${ }^{20}$ but this is an epiphenomenon, a reaction to what could be called a false movement that will disappear rapidly if there are no sustaining factors in the milieu.

\section{- Treatment $^{28}$}

- Explanations and advice on how to keep the TMJ in a state of relaxation.

- An inter-occlusal neuro-muscular relaxation orthesis, or bite block / an orthesis designed to provide slight decompression of the TMJ.

- Short term and mid term reevaluation.

- Search for co-factors factors favoring initiation and encouraging continuation of TMD problems and for an adequate therapy for them.

\section{3 - 5 - Abrupt appearance of articular clicking, preceded by or accompanied by symptoms of maladies of the teeth}

\section{- Clinical signs}

These are identical to those described previously. They appear simultaneously with or just after some malady of teeth. There is a relationship between such dental problems and malfunction of the masticatory system.

\section{- Etiology of the pathosis}

A dental malady such as pulpal necrosis or inflammation of the periodontal membrane, may create a temporary disturbance in static as well as dynamic occlusion causing pain in contact between teeth of opposing jaws that triggers an avoidance reflex and thus prevents jaw closure ${ }^{22,28}$.

Note: this temporary perturbation can be the provocative factor setting off a number of muscular and joint malfunctions $^{14,28}$.

\section{- Treatment}

- Explanations and advice on management of oral functioning.

- Immediate treatment of the dental etiological problem before the short term re-evaluation.

It is imperative for orthodontists to remember that diagnosis of a malfunction of the masticatory system is one of exclusion and that they must first diagnose, that is treat any dental disease or periodontal disorder caused, perhaps, by a sharp edge on an appliance before proceeding with the diagnostic protocol. 


\section{3-6-Rapid onset of peri- articular pain: anterior articular pain associated with malposition of the mandible in maximum intercuspation}

\section{- Motive for consultation}

Rapid onset of peri-articular pain accompanied by occlusal problem.

- Clinical signs ${ }^{21}$

- Anterior articular muscle pain, contra-lateral to the mandibular deviation.

- Slight to moderate pain at rest,

- Intense pain in functioning exacerbated palpation.

- Acute malocclusion, homo-lateral innoclusion, or open bite, with contralateral anterior contacts (fig. 10).

\section{- Diagnosis}

Spasm or reflex wedging of main lateral inferior ptyergoid.

\section{- Pathological etiology}

Reflex shortening chief lateral inferior ptyergoid most often caused by parafunctions such as clenching and bruxism. This shortening modifies mandibular position by provoking a contra-lateral and resultant temporary malocclusion (fig. 11).

\section{- Treatment}

- Explanations and advice on management of oral functioning.

- Injection of local anesthetic without adrenaline in region of lateral inferior ptyergoid,

- Medication with muscle relaxants ${ }^{4}$.

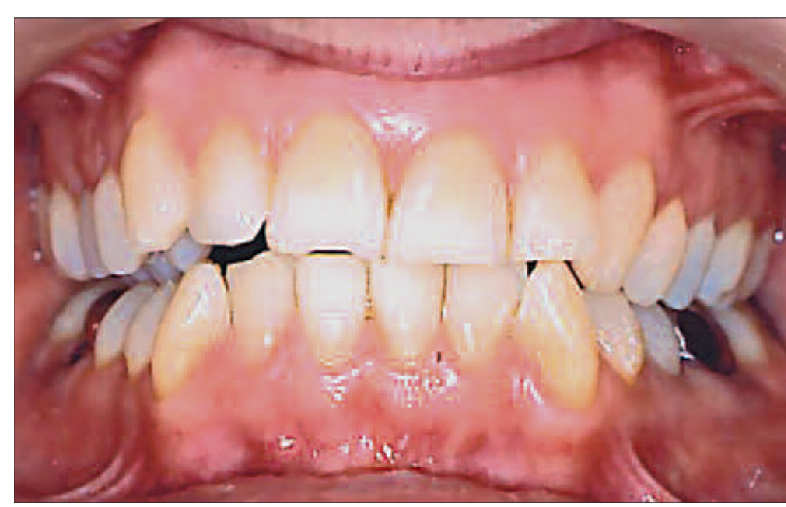

Figure 10

A locking reflex of the lateral ptyergoid muscles has provoked a deviation of the mandible.

- Kinesitherapy to relax the affected muscle, massages, and gymnothérapy $^{2,6}$.

- Neuromuscular relaxation splint.

\section{3-7 - Rapid onset of peri- articular pain following trauma}

\section{- Motive for the consultation}

The patient reports the onset of peri-articular pain after the trauma of rough mastication, blow or shock to the mandible, or cervical sprain with hyperextension.

\section{- Clinical signs}

Concomitant muscular and joint pain:

- Articular pain with signs of inflammation of the capsule and the retrodisc area.

Mobilizing the mandible actively or passively provokes pain particularly when the mandibular movement is homolateral. 


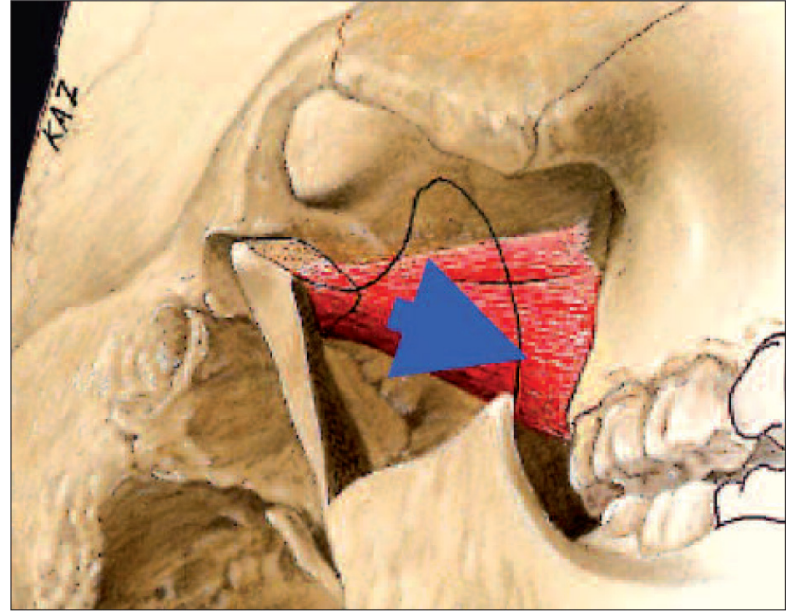

Figure 11

Sketch of the lateral ptyergoid muscle in spasm with shortening of the muscle fibers that caused the mandibular deviation.

Tests for capsular tension are frequently more painful than compression tests.

- Muscle pain following episode of trauma.

Peri-articular, more precisely anterior articular pain only in active mobilization of the jaw.

Capsular distension and articular compression tests may be positive due to the retruded. Compression of the TMJ provokes anterior articular pain.

Note: in these cases the same malocclusion found in the previous type may be present owing to the retro position of the disc caused by swollen retro disc tissues that cause an anterior position of the mandible or a reflex splinting.

\section{- Diagnosis}

- Tempero-mandibular sprain.

- Reflex splinting, a TMJ protective reflex in response to trauma that persists.
- The orthodontist can make a differential diagnosis primarily based on mobilization tests of the mandible, differentiating a sprain from a fracture with a panoramic radiograph.

In both instances the pain is intense, and exacerbated by palpation and both passive and active mobilization of the mandible. Typically the pain felt in fracture cases is exquisite and the TMJ is inflamed as shown by the traditional signs of heat, redness and pain if the fracture affected the condyle.

\section{- Pathological etiology}

- The trauma caused sprain stretches the ligaments.

- Reflex contraction by tissue splinting: the neuromuscular system through its physiological functioning protects joints.

The myotatic reflex in combination with bilaminar stimulation provokes contraction of the muscles opposing the movement activated, making, for example the lateral inferior ptyergoids oppose retraction of the mandible.

\section{- Treatment}

- Explanations and advice on management of oral functioning, with emphasis of patient's putting TMJ almost completely at rest.

- Medication with non-steroid antiinflammatory analgesics and muscle relaxants.

\section{3-8-Abrupt onset of dull jugal or temporal pain}

\section{- Motive for consultation}

Onset of dull, quasi-permanent pain with no specific inciting incident.

\section{- Clinical signs}

- Dull sub-malar or temporal pain. 


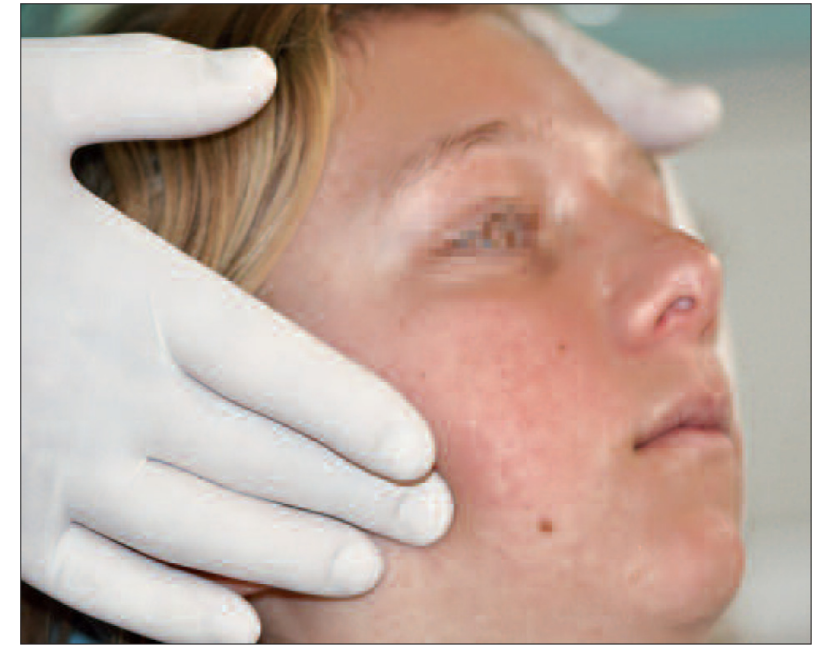

Figure 12

Masseter muscles are enlarged and painful on palpation, caused by indurated bands within them. Maximum intercuspation exacerbates the discomfort.

Palpation of the deep masseter and temporal muscles is painful and indurated bands are perceptible on the elevator muscles ${ }^{38}$.

In palpating the elevator muscles bilaterally during maximum intercuspation orthodontists will note a strong, readily perceptible recruitment of muscle volume (fig. 12).

This type of activity will often be present when patients awaken, after a

\section{4 - CONCLUSION}

Emergency orthodontic visits are by definition delicate. They are unexpected, unplanned, and for patients suffering from pain and anxiety require a complex consultation that orthodontists must complete quickly without the benefit of a substantial and helpful array of diagnostic tools. night when bruxism occurred, and disappear after breakfast or for patients who clench their teeth while awake may appear at the end of the day.

\section{- Diagnosis}

- Curvature of the mandibular elevator muscles,

\section{- Pathological etiology}

- This occurs as a result of an initial non-inflammatory muscle problem that usually represents the first muscular tissue response to a prolonged episode of clenching, a local change associated with muscle fatigue.

- When it is bilateral, the cause is often prolonged muscle contraction related to periods of psychological tension ${ }^{37}$.

\section{- Treatment}

- Explanations and behavioral counseling to reduce tooth clenching.

- Medication with peripheral analgesics and muscle relaxants.

- Physiothérapy ${ }^{15}$ and gymnothérapy $^{27}$.

- Neuromuscular reconditioning with occlusal orthesis ${ }^{35}$.

They in fact, represent the pinnacle of diagnostic difficulty.

Using the case history or intake examination, which allows for elimination of certain hypotheses, and then the clinical examination, precise in nature and based on a clear nosology 
of malfunctioning of the masticatory apparatus, orthodontists must employ to the utmost their clinical acuity to devise a treatment plan, always noninvasive and very conservative, that focuses on the immediate objective of reducing pain and ameliorating function.
In an early follow-up visit they can re-evaluate the situation and prepare a secondary diagnosis, if indicated, to be implemented by conventional therapeutic management ${ }^{2}$.

\section{REFERENCES}

1. Boucher $Y$, Pionchon P. Les douleurs orofaciales diagnostic et traitement. Guide clinique. Paris: CDP, Ed Masson, 2006.

2. Cairns B, List T, Michelotti A, Orbach R, Svensson P. JOR-CORE recommendations on rehabilitation of temporomandibular disorders. J Oral Rehabil 2010 37;481-9.

3. Chihani L. Orientation diagnostique et conduite à tenir devant une limitation de I'ouverture buccale (pp 5-9). In : Stomatologie. Paris : Ellipse, 1989.

4. Carlsson CR. Epidemiology and treatment need for temporomandibular disorders. J Orofac Pain 1999;13:232-7.

5. Chassagne JF, Chassagne S, Deblock L, Gillet P, Kahn JP, Bussienne JE, Pierucci F, Fyad JP, Simon E. Pathologie non traumatique de I'articulation temporomandibulaire. Encycl Méd Chir Stomatol 22-056-R-10, Odontologie, 23-446-D-10, 2003.

6. Choel L. Limitation permanente de I'ouverture buccale (Formes étiologiques et principes de traitements). Trib Dent Réal. Clin 1998;6(1):41-4.

7. CNO Occlusodontologie. Lexique. Paris : Quintessence International ed., 2001.

8. DeBoever J, Carlsson G, Klineberg I. Need for occlusal therapy and prosthodontic treatment in the management of temporomandibular disorders. Part I. Occlusal interferences and occlusal adjustment. J Oral Rehabil 2000;27:36779.

9. De Leeuw R. (ed). Orofacial pain; guidelines for assessment, diagnosis, and management, $4^{\text {th }}$ ed. Chicago: Quintessence Pub. Co.; 2008,129-204.

10. Galdon MJ, Dura E, Andreu Y, Ferrando M. Poveda R, Bagan JV. Multidimensional approach to the differences between muscular and articular temporomandibular patients: Coping, distress, and pain characteristics. Oral Surg Oral Med Oral Pathol Oral Radiol Endod 2006;102:40-6.

11. Giraudeau A. La laxité temporomandibulaire. Info dent 1997;12:795-806.

12. Giraudeau A, Orthlieb JD, Laplanche O, Mantout B, Cheynet F, Chossegros C, Sarrat P. Dérangements intracapsulaires de l'articulation temporomandibulaire, proposition de classification. Cah Prothèse 2001; 114:51-9.

13. Gola R, Chossegros C, Orthlieb JD. Syndrome Algo-Dysfonctionnel de I'appareil manducateur. Paris : Masson, 1992.

14. Guyot L, Thiery G, Brignol L, Chossegros C. Abord conservateur des dysfonctions de I'appareil manducateur. EMC (Elsevier Masson SAS, Paris), Odontologie/Orthopédie dentofaciale, 23-499-A12,2007.

15. Hansson T, Christensen Minor CA, Wagnon Taylor D. Physical therapy in cranio mandibular disorders. Chicago: Quintessence Pub. Co. Inc., 1992.

16. Helkimo G. studies of function and dysfunction of the masticatory system Syst II Index for anamnestic and clinical dysfunction and occlusal state? Swed Dent J 1974;67:101212.

17. Hornaert A Unger F. Désordres temporomandibulaires : les tests cliniques Inf Dent $1997 ; 79(1): 33-5$. 
18. Huang GJ, Rue TC. Third molar extraction as a risk factor for temporomandibular disorder. J Am Dent Assoc 2006;137(11):1547-54.

19. John M.T. Dworkin SF., Mancld LA. Reliability of clinical temporomandibular disorder diagnoses. Pain 2005;118:61-69.

20. Kirveskari $P$, Alanen P. Scientific evidence of occlusion and cranio mandibular disorders J Orofac Pain 1993;7: 235-40.

21. Lachard J, Zattara H, Blanc JI, Cheynet F, Le Retraite G. Ankyloses temporomanibulaires. Paris : Editions techniques. Encycl Med Chir, Stomatologie, 22056-S-15, 1993.

22. Laplanche O. Pédeutour P. Duminil G. Mahler P. Dépistage des anomalies de I'occlusion. Réal Clin 2004;15(2):141-56.

23. Laplanche O, Pédeutour P, Duminil G, Bolla M, Mahler P. Dysfonctionnements de I'appareil manducateur. Paris : Encycl Med Chir, Odontologie, 23-435-E-20, 2001.

24. Laplanche $\mathrm{O}$, Pedeutour $\mathrm{P}$, Orthlieb JD. Que faire face à un bruit articulaire ? Inf Dent 2002;84(5):259-63.

25. List T, Axelsson S. Management of TMD: evidence from systematic reviews and metaanalyses. J Oral Rehabil 2010;37:430-51.

26. Manfredini D, Bucci MB, Montagna F, Guarda Nardini L. Temporomandibular disorders assessment: medicolegal considerations in the evidence-based era. J Oral Rehabil 2011;38:101-19.

27. Michelotti A, De Wijer A, Steenks M, Farella M. Home exercice regimes for the management of non-specific temporomandibular disorders. J Oral Rehabil 2005;32:779-85.

28. Okeson JP. Management of temporomandibular disorders and occlusion, $5^{\text {th }}$ ed. StLouis: Mosby, 2003.

29. Orbach R. Disability assessment in temporomandibular disorders and masticatory system réhabilitation. J Oral Rehabil 2010;37:452-80.

30. Orthlieb JD, Schitly J. Manière-Ezvan A, Brocard D. Occlusodontie pratique. Paris : CDP, 2000:3-11.

31. Palla S. Effets à long terme des traitements des désordres temporomandibulaires. Real Clin1996;7:229-39.

32. Pionchon $P$, Joubert $E$. La fonction de l'entretien clinique avec le malade souffrant d'ADAM. Real Clin 1996;7:159-75.

33. Pullinger AG, Seligman DA, Solberg WK. Temporomandibular disorders. Part II: Occlusal factors associated with temporomandibular joint tenderness and dysfunction. J Prosthet Dent 1988;59:363-7.

34. Pullinger AG, Seligman DA, Gombien JA. A multiple regression analysis of the risk and relative odds of temporomandibular disorders as a function of common occlusal feature. J Prosthet Dent 1993;72:968-74.

35. Re JP, Chossegros C, El Zoghby A, Carlier JF, Perez C, Orthlieb JD. Les gouttières occlusales : pourquoi ? Comment? Quand? Rev Odont Stomat 2009;38:3-16.

36. Rozencweig D. Algies et dysfonctions de l'appareil manducateur. Paris : Cdp,1994.

37. Sato S, Slavicek R. The masticatory organ and stress management. J Stomat Occ Med 2008;1:517.

38. Valentin M, Dowek E, Fleiter B. Pertinence et fiabilité de l'examen clinique dans les désordres temporomandibulaires. Real Clin 1996;7:177-97. 